\title{
Article
}

\section{An Acoustic-based Smart Home System for People suffering from Dementia}

\author{
Eleni Boumpa ${ }^{1, \dagger}$, Anargyros Gkogkidis ${ }^{1, \dagger}$, Ioanna Charalampou ${ }^{1, \dagger}$, Argyro Ntaliani ${ }^{2, \dagger}$, \\ Athanasios Kakarountas ${ }^{1, *,+,}$, and Vasileios Kokkinos ${ }^{3,+}$ \\ 1 Department of Computer Science and Biomedical Informatics, University of Thessaly, Lamia 35131, Greece; \\ eboumpa@uth.gr (E.B.); agkogkidis@uth.gr (A.G.); icharalampou@uth.gr (I.C.) \\ 2 Department of Informatics, University of Piraeus, Piraeus 18534, Greece; p14129@students.cs.unipi.gr (A.N.) \\ 3 Department of Neurological Surgery, School of Medicine, University of Pittsburgh, PA, USA; \\ vasileios.kokkinos@pitt.edu (V.K.) \\ * Correspondence: kakarountas@uth.gr; Tel.: +30-223-106-6723 \\ + These authors contributed equally to this work.
}

\begin{abstract}
Age-in-place can reduce the progress of dementia syndrome and improve the quality of life of the sufferers and their families. Taking into consideration the fact that numerous neurological research results suggest the use of sound as a stimulus for empowering memory of the sufferer, an innovative information home support system for people suffering from dementia is proposed. The innovation of the proposed system is found in its application, to integrate a home system for assisting person recognition via auditory stimulation of the sufferer. Furthermore, the system addresses the need of people suffering from dementia, as well as their familiars, to be recognized by them and have better interaction and collaboration, without the need for training. The system offers an ubiquitous recognition system, using smart devices like smart-phones or smart-wristbands. When a familiar person is detected in the house, then a sound is reproduced on smart speakers, in order to stimulate the sufferer's memory. The system identified all users and reproduced the appropriate sound at 100\% of the cases. To the best of the authors' knowledge, this is the first system of its kind for assisting person recognition via sound, ever reported in the literature.
\end{abstract}

Keywords: Active and Assisted Living; smart speakers; information support system; health care system; sufferer monitoring system; dementia.

\section{Introduction}

Dementia is a set of symptoms that give away intellectual disability (at certain degree) to individuals that have not developed similar behavior before. The first symptom of dementia is the memory loss of things, situations and people. Then the loss of attention occurs, accompanied with the difficulty in speaking and in solving various problems. There are many forms of dementia like Alzheimer's, Vascular Dementia, Dementia with Lewy bodies, Frontotemporal Dementia and other neurodegenerative diseases that end up to dementia, like Parkinson's disease, Epilepsy etc.

Each year, more and more people are diagnosed with dementia. In 2015, 47 million people worldwide were affected, a number expected to increase to 75 million in 2030 and 132 million by 2050 . Although it is a common belief that dementia affects only the elderly, young-onset dementia, that is before the age of 65 years, is accounting for up to $9 \%$ of cases. It should also be pointed out that the progress of the syndrome does not depend on the gender, the social class or the geographical location of the suffering person. [1] A well-known technique that is used in clinics to confront the effects of dementia is music therapy, which will be discussed in a following paragraph.

Phylogenetically, the hippocampus is the most ancient part of the brain cortex. It is located in the medial temporal lobe, in and below the surface of the cortex and is part of the anatomical structures that lie between the cortex and the hypothalamus of the brain (limbic system). It mediates for the 
consolidation of the mnemonic information, i.e. the transfer of information from short-term memory to long-term memory.

The human memory is mainly based on the functionality of the hippocampus in order to synthesize a vivid memory. It seems that the hippocampus connects all the different characteristics of a memory and because of its particular function and its wiring, human beings are able to activate memories simply by the presence of some form of stimulus (e.g. sound, image, scent). Thus, the activation of a stimulus that is stored near the hippocampus has significantly high probability to enable the correct memory, since that part of the brain is less susceptible to the dementia damage.

Therefore, since the hippocampus in the human brain is closer to the primary auditory cortex, the distance that the waves have to go through inside the neurons during the production of an acoustic stimulus is shorter than the distance that they have to go through to reach any other sensory cortex. Thus technically, it is an advantage for any memory stimulating aid to exploit sound as the primary memory stimulus.

Taking into consideration several works found in the scientific literature, it was decided to focus on the auditory stimulus of memory using familiar sounds. The selection was made based on the fact that music and sound have a beneficial effect on people suffering from dementia, in terms of stimulation of memory for past events and activities and the sense of well-being, as presented in [2]. This work, in combination with the work in [3] presenting that sound stimulus helps the sufferer recall his/her identity, with better results than those produced by an optical stimulus, proves that the selection of sound stimulus is beneficial for the sufferer and better in effect than other stimuli. [4]

As mentioned previously, a common technique with positive effect for people with dementia, is music therapy. According to studies [4,5], the effect of music therapy is beneficial for sufferers of dementia as it helps them identify more easily their surroundings and familiars, and also maintain their sense of identity. A notice that has to be made at this point, is that the results from the previously mentioned works were derived during sessions at hospitals or clinics, offering music therapy services. As a conclusion, it can be said that the latter mentioned works proved that sound is an appropriate memory stimulus for people suffering of dementia, and this is the reason for the adoption of music therapy by neurologists and psychologists that take care of people suffering from dementia.

The scope of this work is to exploit the findings of the previous research results and techniques, and propose an acoustic-based memory stimulus system for installation at the sufferer's home. Thus, this will be the first home system of its kind, since the referenced research works were targeting either sufferers at clinics, or require the assistance from a care giver at home. The proposed solution should be considered a novelty in the field of its application (acoustic-based memory stimulus at home), rather than in the field of its implementation. The system will be referenced from hereinafter as AuDi-o-Mentia (derived from audio and dementia). The aims of the proposed home system are: 1) the memory stimulus of the sufferer when a familiar gets closer, 2) the memory stimulus of the sufferer, when a familiar enters the house, while being at a private location, and 3) the detection of the sufferer in the house.

The rest of the paper is organized as it follows. Section 2 provides an overview of previous work for supportive systems at homes of people suffering from dementia, and highlights the differences from the proposed system. Section 3 describes the desired system's operation through use cases. Section 4 describes the architecture of the AuDi-o-Mentia system. Section 5 displays the implementation of the system in hardware and software. Section 6 presents the results and the discussion on them is offered in Section 7. Finally, in Section 8 this paper concludes.

\section{Previous Work}

In recent years, a variety of studies for people suffering from dementia have been presented in the academic literature. A handful of them focused in various approaches to support people with dementia. Some of these works are presented below in chronological order. 


\subsection{Smart Homes for sufferers from Dementia}

In studies [6,7] an Action Recognition System based on Markov Decision Processes is proposed to help people with dementia complete their various day-to-day home activities. A probabilistic learning approach for behavioral patterns in smart homes for people with Alzheimer's has been suggested by Zhang et al.[8]. Both of the works, do not consider recognition of caregivers or familiars of the sufferer. A home automated and unobtrusively monitoring system, to assist the caregivers of the sufferers, using sensing and artificial intelligence technologies is presented at [9]. Richter et al. [10] developed a system to identify the deficiency and the improvement of the need of care at home of sufferers. A user-centred prototype smart home is introduced in [11]. A framework with cameras, wearable devices and sensors, detects and predicts the aggression of people with dementia [12]. A computing platform developed with the use of sensors that are placed at home to monitoring the mood of people with dementia [13]. Another framework assesses the sufferers' progress in daily activities at home and provides decision support systems for their doctor [14]. Kimino et al.[15] developed a sensor system that collects behavioral data, to detect the early symptoms of dementia. While, Schinle et al. [16] are present a support system with sensors, to model the behavior and derive the habits of people with dementia. All the latter mentioned works focus on behaviour monitoring, mainly through a network of sensors installed at the sufferer's home, and not assistance in recognizing his/her familiars and thus increase of their social interaction.

\subsection{Supporting Systems for people with Dementia}

Boger et al. [6] and Jean-Baptiste, Mihailidis [7] have developed an assisting system to guide people with dementia to perform their various day-to-day activities. This work also does not focus on social life rather than day-to-day tasks. Zhang et al. [8] propose a decision support system for the assistive living for people with Alzheimer's. A User Interface able to monitor and remind to the users some information is designed by Ceccacci et al. [17] to support daily activities for people with dementia. These works are based on the eye-brain model, which is not ideal for sufferers from neurodegenerative diseases and syndromes. Mulvenna et al. [13] developed a platform for monitoring the mood and to affect the emotional wellbeing of people with dementia, but not their ability to recognize familiars. Luckner et al. [18] implemented prototypes to support the increase of mobility for people suffering from dementia, limiting the work to autonomy issues and easy movement.

\subsection{Systems for monitoring of people with Dementia}

A wearable and low-cost sensor was implemented for the monitoring of human physical life, the daily living activities and the assisted healthy ageing [19]. A stereo vision-based system was designed for the detection of people with dementia at their home [10]. A monitoring system to assist sufferers' caregivers presented by Osamu et al. [9]. Another monitoring system was developed by using a User Interface [17]. Khan et al. [12] created a framework with a multi-modal sensor network monitoring the behavior of people with dementia. Also, a computing platform that uses sensors has been proposed for the monitoring of sufferers' mood [13]. Kasliwal and Patil [20] proposed a tracking device for people with dementia for the monitoring of their present location, that sends their location to the caregivers' mobile phones. Another tracking and rescue system proposed by Wu et al. [21] integrated at sufferers' shoes that provide their real-time location to their familiars. Alam et al. [22] suggested a wearable sensor-based system for the continuous monitoring of physiological and behavioral parameters of people with dementia. Schinle et al. [16] suggested a system that monitoring the behavior of people with dementia not only in the daytime but also during the night and their bedtime. While Hanna et al. [23] suggest using of Unmanned Aerial Vehicles for the locating of wandering people with dementia. All the previously mentioned works are passive monitoring systems, without actual interaction, mainly for locating the sufferers and either detect suspicious behaviour, or mood change, and as a caregiver automated alert system. Again none of these systems target recognition of familiars by the sufferer, or 
enhancement of his/her social life. Furthermore, sensors and generally the proposed human-computer interface is based on visual control and monitoring and not other, more appropriate, stimulus for interaction.

\subsection{Other suggested systems for sufferers of Dementia}

Tung et al. [24] have compiled a survey with projects that had been proposed by 2013 for the monitoring, assistance, early diagnosis and treatment for people with Alzheimer's disease. Quiz games based on musical and visual stimulus were created by Ferreira et al. [25] for the assistance of their daily living activities for people with dementia. This was the first work that was found to exploit acoustic stimuli. Nishimura et al. [26] developed a system with a 3D animated character for spoken dialogues with people with dementia to support the preservation of their memories, however using again the eye-brain model and the visual stimulus as the main mean to preserve memories. While Siriaraya et al. [27] suggest systems with virtual environments for joint activities of people with dementia with their professional caregivers. Again this work is mainly based on visual stimulus.

\section{Use Cases of the Proposed System}

AuDi-o-Mentia, through disappearing computing, introduces a more physical and efficient way of interaction with the sufferer. The sense of hearing is exploited as a medium to stimulate the memory of the sufferer, and empower memory towards person recognition. Thus, the system is assisting this communication physically, without generating actual technological engagement. An interesting part of the work is the augmentation of a person's identity with an acoustic tag that may be exploited explicitly by the system.

The proposed system has 3 types of users: i) the Familiar, ii) the Sufferer, and iii) the Administrator. The user Familiar is the person whose identity is augmented by a digital acoustic identification (ID) signal,via a device that he/she carries on (smartphone, smartwatch etc). This device provides a unique acoustic tag of the user for identification purpose to the system. Then, this tag is used by the system to reproduce a sound that may be recognized by the Sufferer and be associated to that Familiar person that was identified.

The user Sufferer is the one that is tracked inside the house. He/she bears a device that acts as a beacon. The signal's power is measured by the smart speakers and the sufferer's proximity to each smart speaker is calculated. Then, the closest smart speaker is selected, by the system, to reproduce the associated sound to the ID of any user Familiar that requests so. The Sufferer's identity is also augmented by a digital ID signal, via the device, which is carried on him/her (always hidden from him/her).

The user Administrator is usually a care giver but he/she may be also either the sufferer, or one of his/her familiar people. The main task for the Administrator is to manage the correlation list of sounds/acoustic stimulus with the associated people, and the smart speakers' list.

As mentioned in Section 1, the aims of the proposed home system are: 1) the memory stimulus of the sufferer when a familiar gets closer to him/her, 2) the memory stimulus of the sufferer, when a familiar enters the house, while being at a private location, and 3) the detection of the sufferer in the house. The last aim is describing a geo-fencing feature of the system, since no signal from the sufferer's device triggers an alarm of absence from the household. The operation of the proposed system can be better understood by the following figure, which is used to describe the expected typical use scenarios of the system, depending on the location of the sufferer in his/her home when a familiar enters to it.

\subsection{A typical household}

In Figure 1 a typical household is depicted, including an entrance (door at the left of the figure), a short hall giving access to a bathroom, a bedroom and the living room that includes a kitchen. A balcony is also part of the household. Smart speakers are placed, in the interior of the house, covering all rooms, as well as, to exterior locations, such as the balcony. 
Speakers are illustrated as squares named with letters (A-E). Also, a router connecting the home network with Internet is implied, although not illustrated for simplicity reasons. For better describing the use cases, two locations that are circled and enumerated are provided. These are locations where the sufferer may be found.

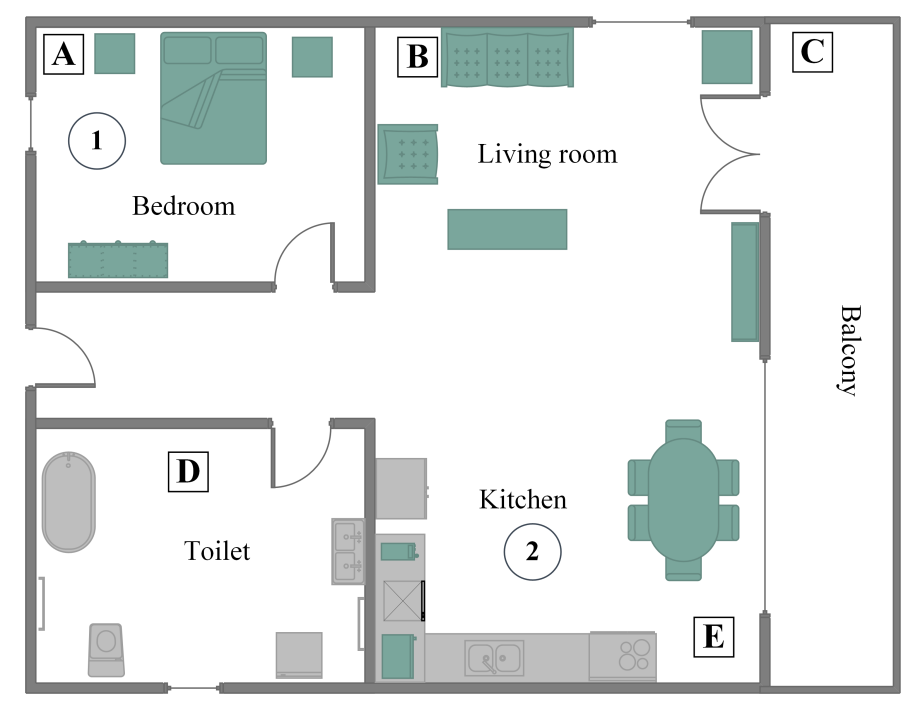

Figure 1. A typical household for a sufferer of dementia.

\subsection{Notifying Sufferer for a nearby Familiar}

In Figure 1 a use case of a familiar entering the room, where the sufferer is found, is considered. The sufferer is found at location 2 (circled), which is part of a greater room. Although the familiar is between two smart speakers ( $B$ and E squares), only speaker $E$ is activated, recognizing that the sufferer is closer to it. This use case, is the main function of the system. That is, stimulate the sufferer's memory by reproducing a characteristic sound to the Familiar. In order to achieve this, a unique ID is required for each Familiar, which is matched in the cloud database with the characteristic sound. The identification (automated or semi-automated) of the Familiar's ID is one of the two main technical goals of the system.

\subsection{Sufferer at a private location}

In Figure 1, a use case of a familiar entering the house when the sufferer is found at a private location, is considered. There are cases when the a Familiar is not given access to a room, however there is the need for notifying the sufferer. That is exactly the same case as the previous one, however it shows one requirement for the proposed system that is not included to any other similar solution. That is memory empowerment without eye contact but rather via sound stimulation. In this case again the familiar is identified by the system, the closer smart speaker to the sufferer (square D), reproduces the corresponding characteristic sound, and the sufferer is informed for the familiar's presence at home.

\subsection{Detecting Sufferer's location}

In Figure 1 a use case of a familiar trying to spot the sufferer in the house is considered. In this use case, we suppose that the sufferer is found at the bedroom (circled 1). That is the second of the two main technical goals of the system. This technical issue offer two features to the system. The first one is the discovery of the sufferer from the Familiar by activating the closest to the Sufferer smart speaker. The second feature is a form of geo-fencing, that is the digital limitation of the Sufferer in the bounds of the house. Detection of the Sufferer is achieved also either automatically or semi-automatically.

In the first case, the familiar requests from the system to activate the smart speaker that is closer to the Sufferer (square A), in order to spot her/him in the house (localization is achieved through the 
digital ID that the Sufferer transmits, similarly to the Familiar). The second case, is the activation of the closest to the Sufferer smart speaker in explicitly defined time periods. If the ID of the Sufferer is not detected, that means that the Sufferer is out of range of the smart speakers' network. This allows automatic detection of presence (or not) of the Sufferer in the house.

\section{Architecture of the Proposed System}

The architecture of the proposed system is server-centric, allowing access to the users, and the devices, via the appropriate client software. The proposed system offers a Software-as-a-Service (SaaS), which associates Sufferers with Familiars, and is controlled by the Administrator.

The communication of the system is design with concern to two operations, namely the system administration and the sufferer support.

The first one is defined by the administration procedures. These procedures include the creation of a user (Sufferer or Familiar), the inclusion of familiars to a sufferer's list, the association of sound files between user pairs and finally, the management of the smart speakers (i.e. registration and remove of a speaker). Furthermore, it includes also the registration of specialized hardware (for identifying the user's ID, like a wristband or a smart phone of a familiar, or a digital ID device for monitoring the sufferer).

The second operation of communication concerns the support of the sufferer. That includes is stimulation by the identification or enabling of a digital ID (familiar that enters the house), that produces the reproduction of an associated sound/music file to the speaker that is founded nearer to the sufferer. This is achieved by creating initially a communication channel between the digital ID device of the familiar and the targeted smart speaker. Then the smart speaker requires from the cloud-based service the associated sound/music file and then reproduces it.

In Figure 2, an abstract representation of the system's architecture is depicted, exhibiting all the components of the system and their interaction. Notice a black line denotes communication based on IEEE 802.xx (either Ethernet or Wi-Fi) and a blue line denotes a Bluetooth communication channel.

The architecture of the proposed system was selected following the paradigm of the leading enterprises in the field of smart speakers. The processing of each request is executed on a cloud-based infrastructure. Since the AuDi-o-Mentia system is not targeting a safety-critical application, the selection of the cloud-based architecture is considered efficient. Although, any other architecture selection (such as Fog or Edge) [28,29] might be proven beneficiary in terms of availability and performance of the system, it would however lead to additional requirements for a custom-owned platform and the design (and production) of new smart speakers. Then, this selection would turn the system costly and extremely dependant to one vendor. Furthermore, it will eventually require new design effort to be spent for considering scaling up issues as well as installations problems for the new smart speaker. Finally, it wouldn't take advantage of any smart speaker already available in the market, which may be connected with software modifications to the proposed system. Thus, for compatibility reasons, the cloud-based architecture was selected.

In the following subsections, information regarding the architecture in terms of communication protocols, infrastructure, software and hardware resources are detailed. 


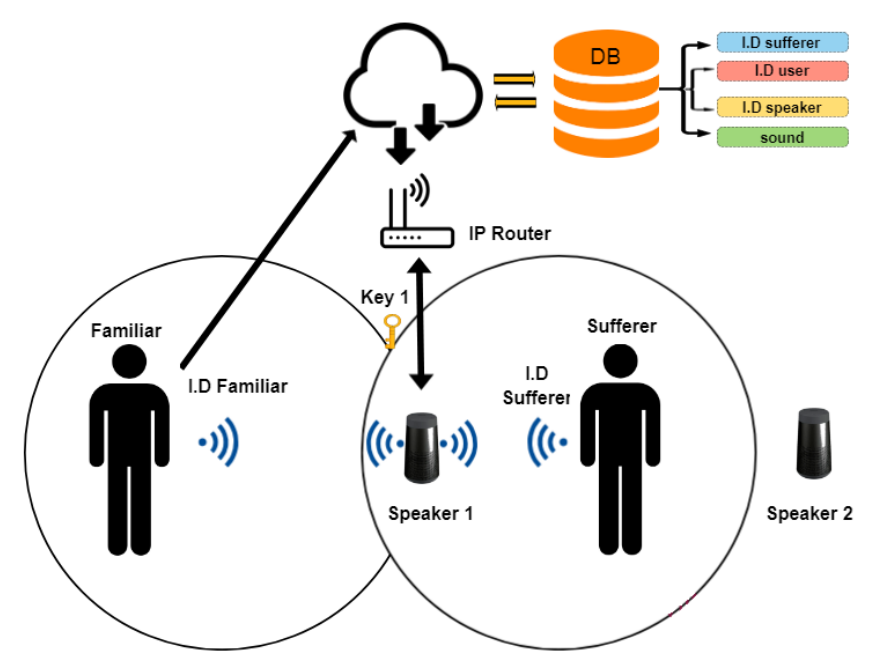

Figure 2. A representation of the system's architecture at a user-communication level.

\subsection{Cloud}

For the needs of the application, there is an available Virtual Machine (VM) on a Cloud infrastructure, that mainly hosts a database (DB) schema. On the DB, data regarding the sufferer and the familiars are stored. A table that holds the correlations between the sufferer and the familiar with the characteristic sound and the duration, is included to the DB schema. Also, there is a table that holds the relations between the sufferer and the smart speakers. On top of that DB, there are some services in order to handle the interaction. By using services, the software can be splitted and take advantage of tools and technologies that best fit each time. On the next layer there is a REST API in order other devices to interact with those services. In Figure 3, the cloud architecture is depicted, as described before.

As seen in Figure 3 the cloud services may be accessed either via a computer, a tablet and a smartphone or a smart speaker. In the first case, the users Familiar and Administrator are communicating with the cloud service. The user Familiar is connecting to the system in order to register and apply to be associated with a Sufferer. The Administrator is contacting the cloud services in order to manage the database and grant/create the appropriate associations between the Sufferer and the Familiars. The second case, corresponds to the communication of the system with the smart speakers, in order either to ask for information regarding the position of the Sufferer, or to stream sound directly to the smart speaker that was identified as the closest to the Sufferer. 


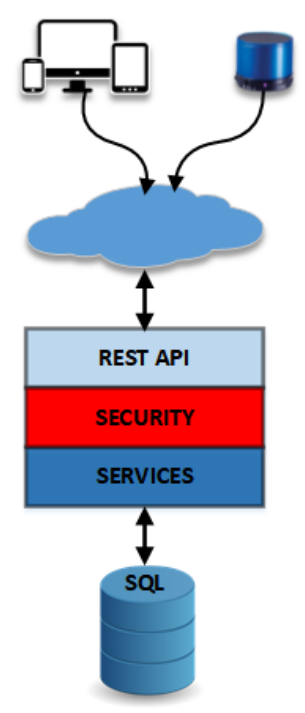

Figure 3. The cloud architecture of the AuDi-o-Mentia system and its components.

\subsection{Smart Home}

In the Smart Home there are speakers with the ability to connect either via Bluetooth or Wi-Fi with the system. The use of Bluetooth allow the establishment of communication with the user Familiar in order to activate the operation of notification of his/her presence, or the detection of the Sufferer in the house. Furthermore, the Sufferer is submitting a beacon signal in order to make his/her presence known. The use of the Wi-Fi aims the communication with the cloud services, in order to submit requests from the Familiar to the Cloud or to submit requests from the Cloud to the smart speakers. Especially for the reproduction of the associated sound with a Familiar, a detailed process chart is depicted in Figure 4 including the communication between the user, the smart speaker and the cloud .

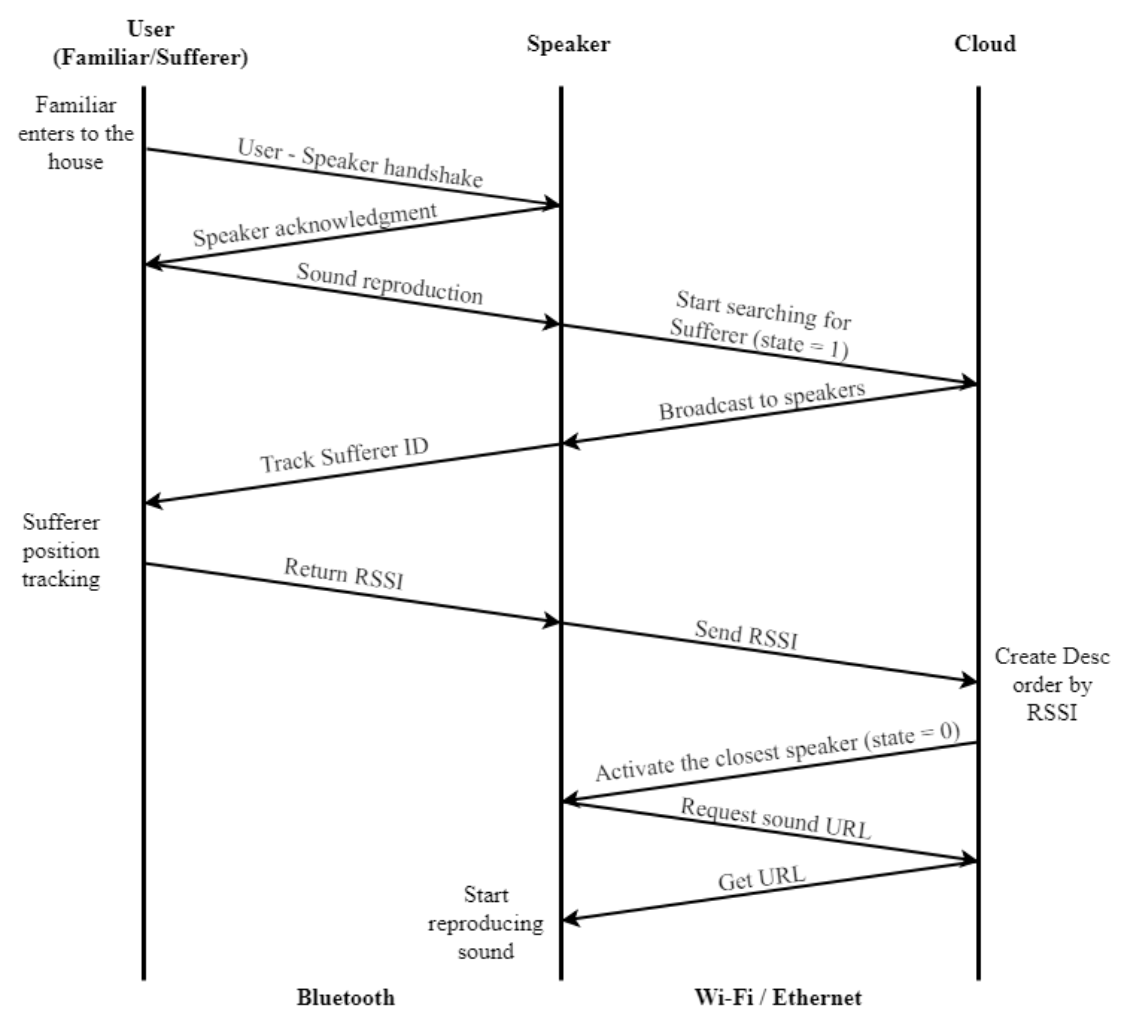

Figure 4. Communication from the entrance of a Familiar to a Sufferer's house until the reproduction of the associated soundmusic. 


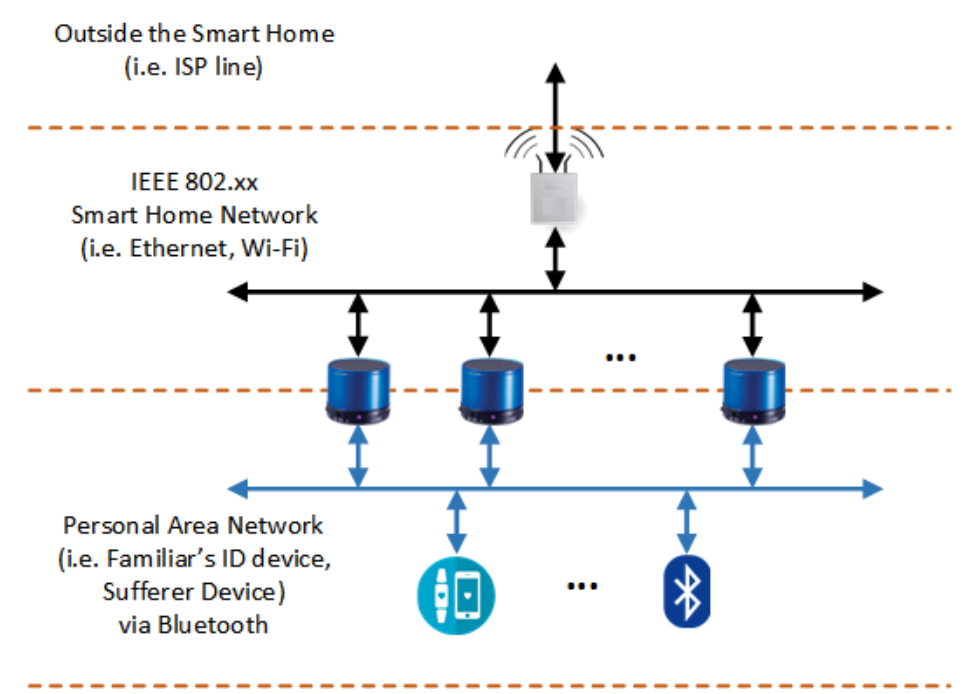

Figure 5. Topology of the smart speakers' network in the smart home.

The speakers' network at the smart home, is the bridge between the user interaction and the cloud service. Each smart speaker is connected via both Ethernet/Wi-Fi and Bluetooth. The topology of the smart speakers' network is depicted in Figure 5. As it may be seen, any device from the users (either Familiar or Sufferer) is connected to the speakers, and through them to the cloud. Access to the cloud is achieved via the house's installed ISP router.

\section{Implementation}

In the implementation of the proposed system, all data transfers between Cloud/Server and the devices is being performed using the JavaScript Object Notation (JSON) format.

Also, every network packet from/to the service layer is encrypted using AES block cipher, for security reasons. Moreover, information like passwords or the MAC address of the smart speakers (or any other device that might be needed) are encrypted using SHA256 hash function.

\subsection{Cloud/Server Side}

The server application was developed on Azure as a web service. The database schema is designed using MSSQL and all the current developed services/REST API were developed using PHP. All the users of the system (Sufferer, Familiar/caregiver) have to register and get their unique ID's. Therefore, there is a service designed to handle the administrator actions along with some views. On the following figures (Figure 6, Figure 7), there are the views of the administrators dashboard and the action to edit a correlation. Moreover, there are services to handle the actions of the speakers and the familiar. Those will be described on the following subsections.

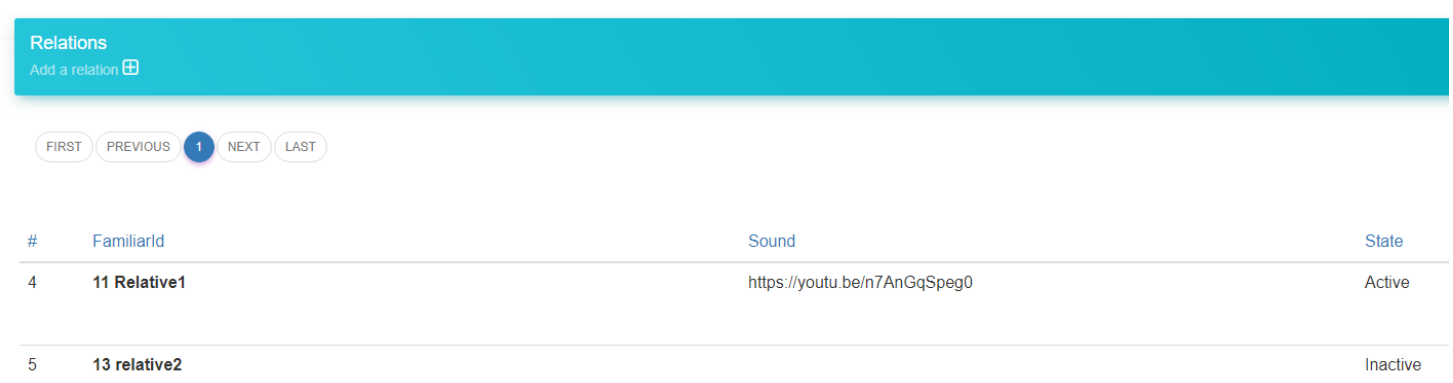

Figure 6. Sufferer (administrator) dashboard. 


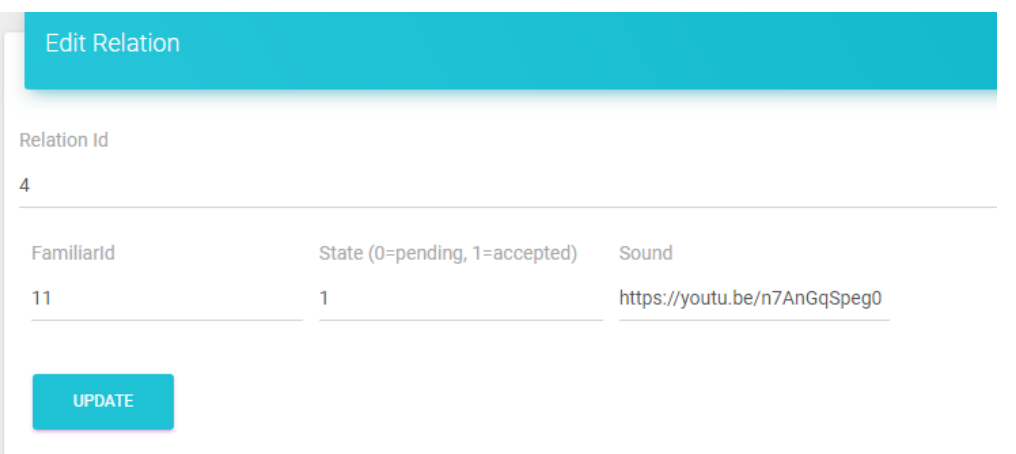

Figure 7. Managing the association of a Familiar to a characteristic sound.

\subsection{Smart Home}

In order to develop the prototype of a smart speaker, a Raspberry Pi 3 Model B+ is used, an open source hardware platform. As an Operating System (OS) the Raspbian Stretch is used, and a Bluetooth server was developed using Python programming language. Also, a script is used as a Dynamic Domain Name System (DDNS), in order to keep the Cloud services up to date regarding the connection. On boot of the OS, Bluetooth server is loaded and a cron job executes a script every 24 hours in order to update connection information to the Cloud (the DDNS task).

The Bluetooth server, accepts a connection from a familiar's device and it initiates the exchange of some messages as custom handshake. After that, the familiar's device will be recognized and a message to the Cloud REST API will be send to retrieve the associated sound. During this process, the service on the Cloud before sending the sound URL, will notify that the smart speakers have to track the Sufferer's position, in order to determine which speaker is the closest to him/her. In order to achieve tracking, a custom wearable device is found on the sufferer (wearable device, suggested to be sewn in clothes) and by using a command on OS level, the smart speaker can retrieve the Received-Signal-Strength-Indicator (RSSI) value Figure 8. After that, the speaker sends the RSSI value to the Cloud and another service is responsible to determine which speaker is the closest to the sufferer, [30]. Then, the URL of the correlated sound will be send to that speaker only in order to start reproducing the sound. 


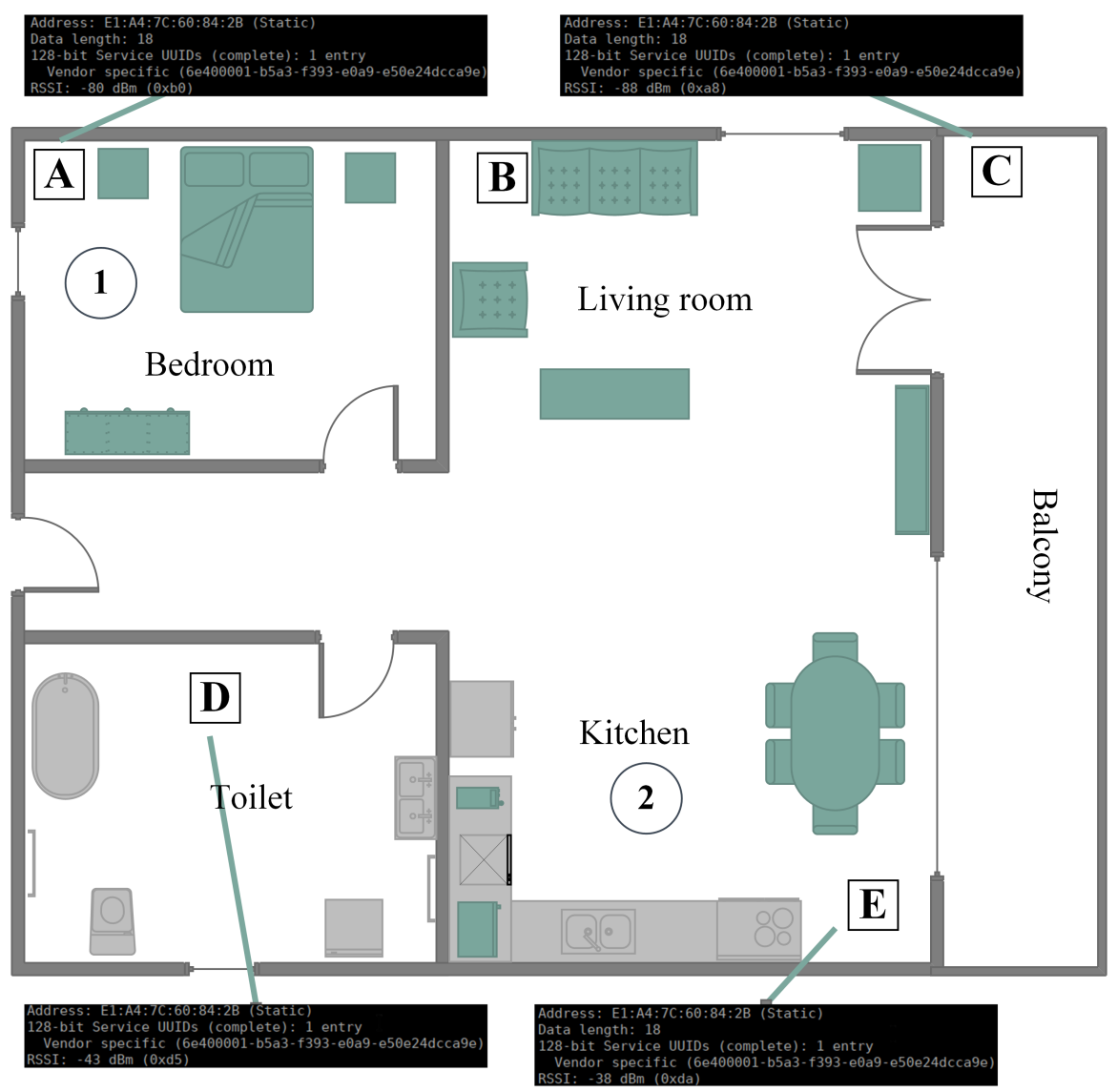

Figure 8. Searching for RSSI value.

The calculation of the RSSI is based on the general description of positioning and triangulation, as described in [31]. The difference based on the aforementioned work, is that the system is interested only for the smart speaker that is closer to the sufferer. This means that there is no need for correlating three sources in order to position the beacon (hence the Sufferer's ID device) but only identify the smart speaker that detected the higher RSSI. This RSSI in turn corresponds to the shortest distance to the Sufferer. Based on research on positioning using Bluetooth 4.0, it appears that RSSI and Time-of-Flight are the preferred methods to locate a Bluetooth beacon [32-34].

When there is the need from the system to detect the sufferer, that is find the closest smart speaker, the following equation is utilized:

$$
R S S I=-\left(10 n \log _{10} d+A\right)
$$

where $n$ and $A$ are known as Radio Frequency (RF) parameters to describe the network environment. The parameter $A$ is defined as the absolute energy, represent by $\mathrm{dBm}$ at a distance of 1 meter from the transmitter; $n$ is the signal transmission constant, and it is relevant to signal transmission environment. Finally, $d$ is the distance from the transmitter node to the receiver node.

As it may be observed from the Figure 8, each smart speaker returns a unique RSSI, corresponding to the power of the signal received by the Sufferer's ID device. Then these measures are submitted to the system and after descending sorting, the smart speaker of the highest RSSI is selected as the closest to the Sufferer.

\subsection{Mobile Application}

The smart phone application used by the familiar was developed using Android Studio targeting Android version Marshmallow (API level 23) and above. The Android Studio was selected because it builds native applications for the Android platform, optimized for the targeted hardware platform. 
The user Familiar logins to the application, from which it is possible to select the sufferer with whom he/she will interact (it is not uncommon for relatives of sufferers, to also suffer from Dementia). The selection of the sufferer (Figure 9a), fetches to the application the list of speakers (Figure 9b) that have been registered by the Sufferer in the smart home. Management options for the smart speakers are included in the application. Finally, the Familiar may connect to the Wi-Fi home network (Figure 9c), for accessing directly with the cloud services.

When the Familiar enters the smart home, he/she taps the play button and a request for sound reproduction is sent to the system installed on the cloud. At this point, the system requests from all speakers to report their relative position compared to the Sufferer. The RSSI of the Sufferer's ID device is measured, and the higher is selected. Since the higher value is expected to be reported by the speaker that is closer to the Sufferer, the Sufferer's position is detected in relation to the closest speaker.

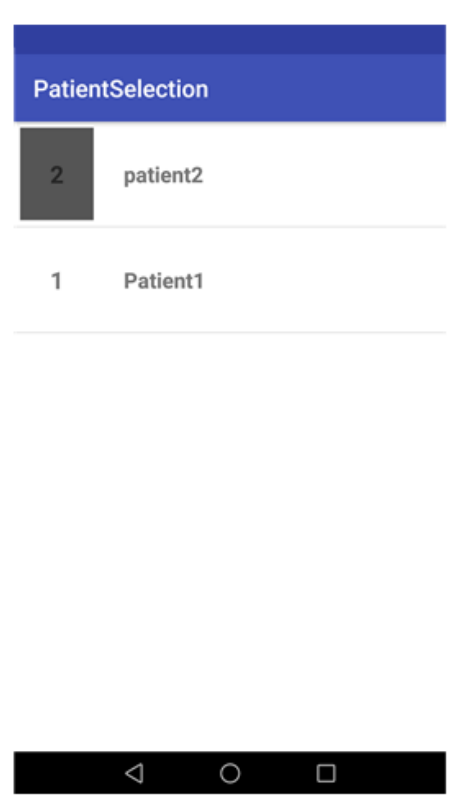

(a)

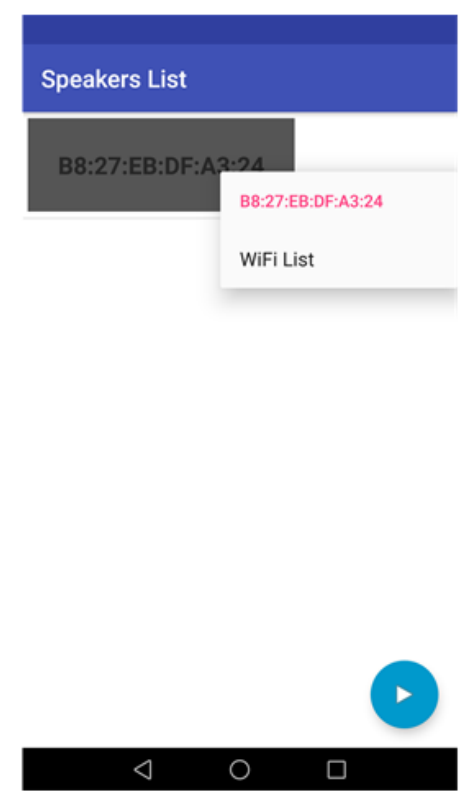

(b)

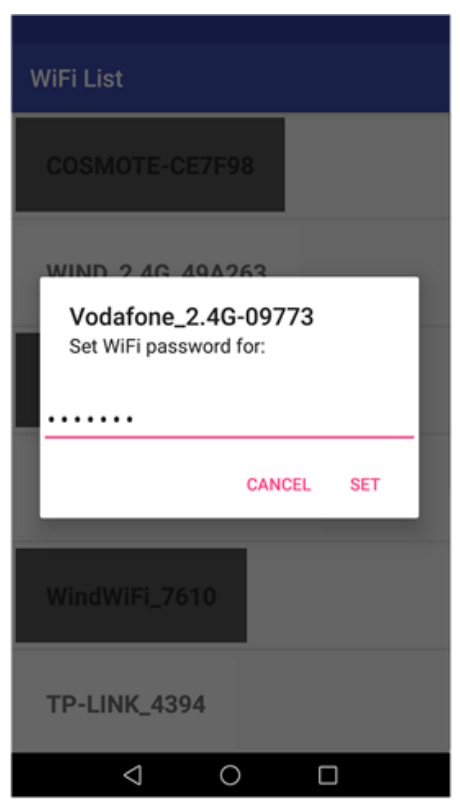

(c)

Figure 9. (a) Select for associated sufferer, (b) Manage smart speaker, and (c) Set Wi-Fi connection for the smart speaker.

\section{Results}

The aim of this work is to exploit the findings of previous research works and propose an acoustic-based memory stimulus system for installation at the sufferer's home. Thus, in this Section the functionality of the proposed system is tested and evaluated. The benefits of memory stimulation via sound is out of the scope of this work, since it has already been proved in other referenced works [2-5]

The proposed solution should be considered a novelty in the field of its application (acoustic-based memory stimulus at home), rather than in the field of its implementation. The system will be referenced from hereinafter as AuDi-o-Mentia (derived from audio and dementia). The aims of the proposed home system are: 1) the memory stimulus of the sufferer when a familiar gets closer, 2) the memory stimulus of the sufferer, when a familiar enters the house, while being at a private location, and 3) the detection of the sufferer in the house.

For the evaluation of the proper functionality of the system, experimental tests were carried out. The tests took place in a large, rectangular room, in which 3 smart speakers were placed, as seen in Figure 10. The formation of the speakers as they were placed in the room, could be linked to a scalene 
triangle, with the two vertices of the triangle corresponding to the two corners of one wall of the room, and the third vertex in the middle of the opposite wall.

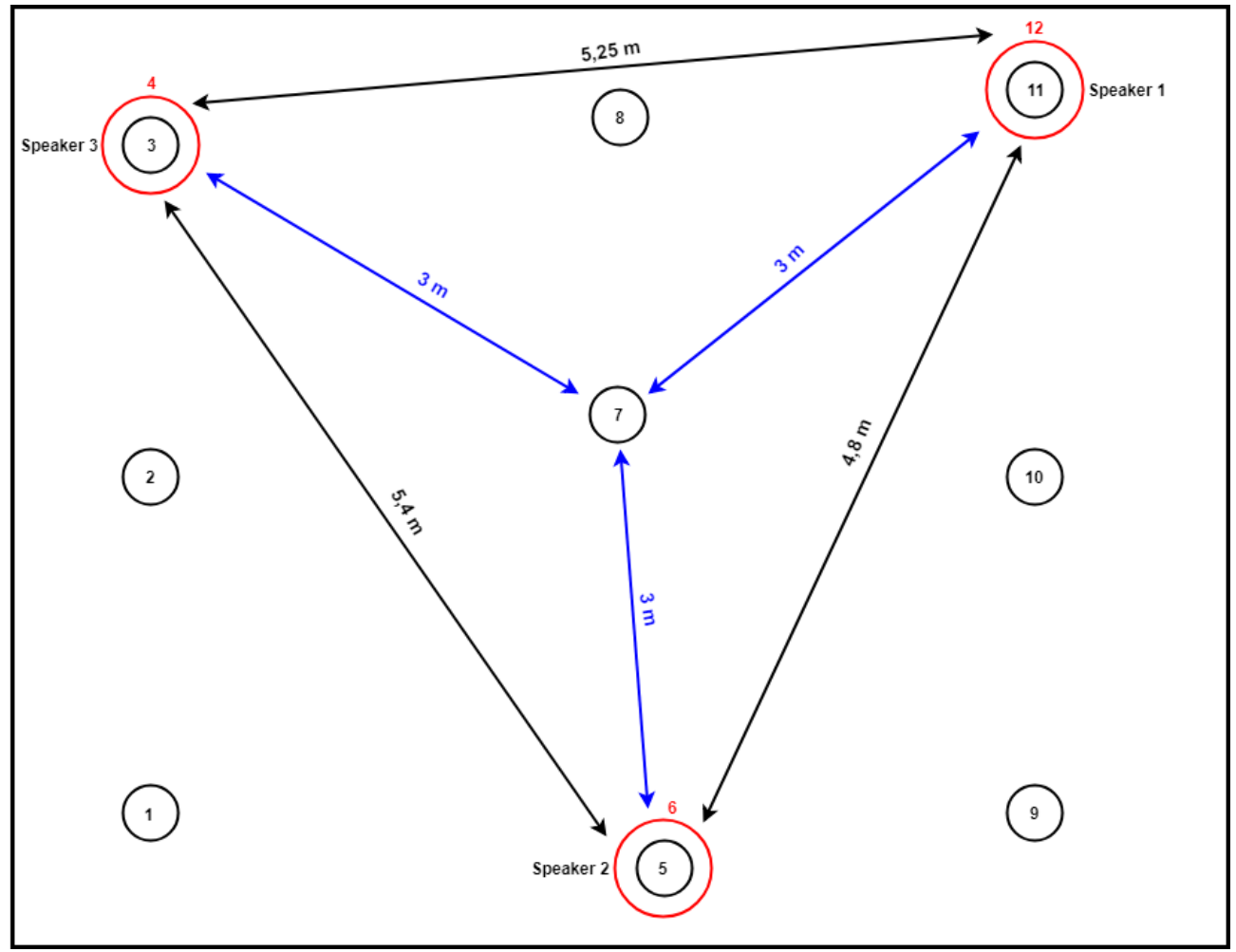

Figure 10. Topology of smart speakers in the room, where the tests took place.

\subsection{Set of tests}

For evaluation purposes, 24 different configurations were performed in total, specifically 2 sets of 12 configuration tests. Two users Familiars were considered, in order to evaluate identification of the user in the room, and one Sufferer. The difference between the 2 sets of tests was the ID device that each Familiar carried with him/her. In both 2 sets, and for reasons of fairness to the maturity of the technology, the ID device was a smartphone, with one device supporting Android Marshmallow (API level 23) and the other one supporting Android Nougat (API level 24). In both sets of configurations, the sufferer's position in reference to the speakers' position, was almost the same.

The number of configurations for test purposes is considered satisfactory. Examining the works reported in Sections 1 and 2, for applications of sound as memory stimulus, it is observed that only few works exist. In Table 1, the previous works are reported (as referenced in [35]). The number of the participating persons is small and in the cases that more than 3 people participated to the evaluation, training was required, thus a larger sample size was necessary.

For categorization reasons, each set was associated to one and only Familiar. Furthermore, in the 12 test configurations that were performed, the position of the Sufferer is examined, regarding his/her proximity to one of the three smart speakers in the room. Additionally, the case of being between two smart speakers was considered.

\subsection{Positioning of the Sufferer}

When a request from the system is sent to the smart speakers to detect the position of the Sufferer, all of them are trying to detect the Bluetooth signal of the ID device of the Sufferer. The measure is the RSSI as reported by the Bluetooth module of the smart speaker. Based on Equation 1, the highest the returned value from a speaker, the shortest the distance from the Sufferer. 
Table 1. Projects reported in the scientific literature regarding dementia and sound as a stimulus for memory

\begin{tabular}{|c|c|c|c|c|c|}
\hline Authors & Year & Title & Type of device(s) & Type of study & Sample size \\
\hline $\begin{array}{l}\text { Arntzen et al. } \\
\text { [36] }\end{array}$ & 2016 & $\begin{array}{l}\text { Tracing the successful } \\
\text { incorporation of } \\
\text { assistive technology } \\
\text { into everyday life for } \\
\text { younger people with } \\
\text { dementia and family } \\
\text { carers }\end{array}$ & $\begin{array}{l}\text { Pre-developed } \\
\text { devices - TV remote } \\
\text { control, simple } \\
\text { mobile phone, digital } \\
\text { calendar, GPS, } \\
\text { speaking watch, } \\
\text { medicine dispenser, } \\
\text { stove timers, } \\
\text { electronic door lock }\end{array}$ & Evaluation & $\begin{array}{l}12 \text { people } \\
\text { with dementia } \\
\text { and } 14 \text { family } \\
\text { carers }\end{array}$ \\
\hline $\begin{array}{l}\text { Imbeault et al. } \\
\text { [37] }\end{array}$ & 2016 & $\begin{array}{l}\text { Impact of AP@LZ in } \\
\text { the daily life of three } \\
\text { persons with } \\
\text { Alzheimer's disease: } \\
\text { Long-term use and } \\
\text { further exploration of } \\
\text { its effectiveness }\end{array}$ & $\begin{array}{l}\text { AP@LZ smartphone } \\
\text { application }\end{array}$ & Trialling & $\begin{array}{l}3 \text { people with } \\
\text { "Alzheimer's } \\
\text { disease }\end{array}$ \\
\hline $\begin{array}{l}\text { Chen et al. } \\
\text { [38] }\end{array}$ & 2015 & $\begin{array}{l}\text { MemAid - A } \\
\text { therapeutic } \\
\text { application for } \\
\text { dementia patients } \\
\text { and caregivers }\end{array}$ & $\begin{array}{l}\text { Android application } \\
\text { for mobile phone } \\
\text { with: Memory Game, } \\
\text { Reminders, Real-time } \\
\text { Location Alert } \\
\text { System }\end{array}$ & $\begin{array}{l}\text { Development } \\
\text { and testing }\end{array}$ & Not specified \\
\hline $\begin{array}{l}\text { Orpwood et } \\
\text { al. [39] }\end{array}$ & 2007 & $\begin{array}{l}\text { Designing technology } \\
\text { to support quality of } \\
\text { life of people with } \\
\text { dementia }\end{array}$ & $\begin{array}{l}\text { Four prototypes: } \\
\text { Music player, } \\
\text { Window-on-the-world, } \\
\text { Conversation } \\
\text { prompting, Sequence } \\
\text { support }\end{array}$ & $\begin{array}{l}\text { Development } \\
\text { and trialling }\end{array}$ & $\begin{array}{l}26 \text { people } \\
\text { with dementia }\end{array}$ \\
\hline $\begin{array}{l}\text { Orpwood et } \\
\text { al. [40] }\end{array}$ & 2004 & $\begin{array}{l}\text { User involvement in } \\
\text { dementia product } \\
\text { development }\end{array}$ & $\begin{array}{l}\text { Picture Gramophone, } \\
\text { Night and Day } \\
\text { Calendar, Locator, } \\
\text { Tap Monitor, } \\
\text { Automatic Nightlight, } \\
\text { Gas Cooker Monitor }\end{array}$ & Development & $\begin{array}{l}\text { Personal } \\
\text { carers, } \\
\text { professionals, } \\
\text { engineering } \\
\text { designers, } \\
\text { people with } \\
\text { dementia - } \\
\text { numbers not } \\
\text { specified }\end{array}$ \\
\hline $\begin{array}{l}\text { Yashuda et al. } \\
\text { [41] }\end{array}$ & 2002 & $\begin{array}{l}\text { Use of an IC Recorder } \\
\text { as a voice output } \\
\text { memory aid for } \\
\text { patients with } \\
\text { prospective memory } \\
\text { impairment }\end{array}$ & Sony IC Recorder & Trialling & $\begin{array}{l}8 \text { people with } \\
\text { dementia }\end{array}$ \\
\hline
\end{tabular}

To evaluate the monitoring process of the Sufferer in the room, the 12 configuration tests were conducted (at each predefined point) in the room, as depicted at Figure 10. As seen in Table 2, positioning was successful for all tests.

The reported values are the median value of the tests for each configuration. 
Table 2. Detecting position of Sufferer, based on the Bluetooth ID device RSSI, as measured by the smart speakers. The measures correspond to the first test set (user=Familiar1).

\begin{tabular}{|c|c|c|c|c|c|}
\hline Position & Speaker 1 & Speaker 2 & Speaker 3 & Success in positioning & Success in reproduction \\
\hline 1 & -90 & -77 & -89 & $\sqrt{ }$ & $\sqrt{ }$ \\
\hline 2 & -90 & -72 & -83 & $\sqrt{ }$ & $\sqrt{ }$ \\
\hline 3 & -84 & -83 & -52 & $\sqrt{ }$ & $\sqrt{ }$ \\
\hline 4 & -89 & -88 & -67 & $\sqrt{ }$ & $\sqrt{ }$ \\
\hline 5 & -75 & -37 & -75 & $\sqrt{ }$ & $\sqrt{ }$ \\
\hline 6 & -77 & -70 & -87 & $\sqrt{ }$ & $\sqrt{ }$ \\
\hline 7 & -69 & -74 & -67 & $\sqrt{ }$ & $\sqrt{ }$ \\
\hline 8 & -78 & -77 & -68 & $\sqrt{ }$ & $\sqrt{ }$ \\
\hline 9 & -84 & -65 & -85 & $\sqrt{ }$ & $\sqrt{ }$ \\
\hline 10 & -68 & -80 & -75 & $\sqrt{ }$ & $\sqrt{ }$ \\
\hline 11 & -53 & -76 & -75 & $\sqrt{ }$ & $\sqrt{ }$ \\
\hline 12 & -62 & -78 & -78 & $\sqrt{ }$ & $\sqrt{ }$ \\
\hline
\end{tabular}

In Table 2, there is one more column at the end, that corresponds to the results of the tests reported in the following subsection.

\subsection{Reproduction of sound by the appropriate speaker}

The two sets of tests were considered for two different users. The scenario, of the evaluation, considered a Familiar entering the room and the activation of the system via his/her ID device. The evaluation's scope is the reproduction of the correct sound, that is the one associated with the Familiar's ID. In Tables 2 and 3, the results for the two test sets are reported.

Table 3. Detecting position of Sufferer, based on the Bluetooth ID device RSSI, as measured by the smart speakers. The measures correspond to the second test set (user=Familiar2).

\begin{tabular}{ccccc}
\hline Position & Speaker 1 & Speaker 2 & Speaker 3 & Success in reproduction \\
\hline 1 & -90 & -81 & -91 & $\checkmark$ \\
2 & -80 & -75 & -75 & $\checkmark$ \\
3 & -76 & -85 & -30 & $\checkmark$ \\
4 & -75 & -80 & -63 & $\checkmark$ \\
5 & -88 & -17 & -73 & $\checkmark$ \\
6 & -78 & -70 & -77 & $\checkmark$ \\
7 & -65 & -65 & -68 & $\checkmark$ \\
8 & -62 & -74 & -80 & $\checkmark$ \\
9 & -71 & -65 & -88 & $\checkmark$ \\
10 & -72 & -81 & -81 & $\checkmark$ \\
11 & -34 & -88 & -86 & $\checkmark$ \\
12 & -63 & -77 & -93 & \\
\hline
\end{tabular}

\section{Discussion}

The previous Section had two major targets to evaluate; first, check if identification of a Familiar is successful (that is correct reproduction of the associated sound/music per user), and second, the successful detection of the sufferer. The latter proved to be the most difficult to be achieved. In the rest of the paper, the results are discussed and considerations are reported.

The results of the previous Section show that the embedded application to the users' devices manage to provide to the system the appropriate credentials, for identification reasons. That is the MAC address and the ID of the user. From the total number of tests, all were successful in reproducing the appropriate sound. The time interval from button press until the reproduction of the sound was 
measured in few seconds, allowing the spontaneous reaction from the user in case of malfunction. Since correct functionality in $100 \%$ of the test cases was verified, no more actions were taken.

The most challenging part of the evaluation of the proposed system was the detection of the sufferer, since the sound is expected to be reproduced by the closest to the sufferer speaker.

The process is relaxed and limited to the detection of the area around the Sufferer. The approach that was used is the direct exploitation of the RSSI values, as reported by the smart speakers when scanning for the Bluetooth signal of the Sufferer's ID device. The previously presented results of the conducted tests show that the reported RSSI is sufficient as an indicator.

For comparison reasons, the proposed work is included in Table 4 where other works are also reported. The works are examined for the following issues: 1) Training (if there is the need for training the Sufferer or the Familiars), 2) Home (system applicable for home use), 3) Familiars (system considers the familiars and the caregivers as users), 4) Developed (or just proposed), 5) Evaluation (the system was evaluated in simulation), 6) Test (the system was evaluated for functionality), 7) Trial (system tested in real conditions), 8-10) Stimulus (memory stimulus based on vision, audio, haptic respectively), 11) Memory empower, 12) Sample size (Familiars and in parenthesis the sufferers). The comparison table show that the proposed work is the only one that do not need training for the users, it is suitable for home use, it is developed and tested, it is based on audio, it empowers memory and at the same time consider the Familiars as users. Notice that in most works, that may be applied at home, the sample size is kept low mainly due to difficulty, that we also faced, for getting grant from familiars of the sufferer to install the system in their house.

Future research includes the design of a new series of smart speakers based on the developed prototype, allowing automatic and more precise communication with custom-made ID devices for the users. Especially in the case of the Sufferer, precision is an issue when he/she is found in the middle between two speakers. Thus, dynamic priority assignment should be considered in order to allow possible conflicts. Alternatively, a machine learning procedure is also considered as a solution to this problem. Furthermore, new methods to detect the Sufferer, such as Time-to-Flight approach should also be examined. Moreover, another contribution of this work, that has to be evaluated, is the development of a tool for professionals providing music therapy sessions. This tool may allow the increase of the music therapy sessions in time and its benefits.

Finally, for the future development of the proposed system, alternative configurations will be considered, such as those targeting higher performance and availability. A custom designed gateway should be developed to meet the requirements (Wi-Fi, Bluetooth communications) of the proposed system in order to store data that are being used often and work as a cache layer between the Cloud and the smart speakers. By using that gateway, we can decrease significantly the latency of the communication between the devices, reduce processing time of data, and reduce the needs of a stable internet connection.

\section{Conclusions}

In this paper, a novel solution for people suffering from Dementia was presented. The innovation of the proposed system is found in its application, to integrate a home system for assisting person recognition via auditory stimulation of the sufferer. Furthermore, the system addresses the need of people suffering from dementia, as well as their familiars, to be recognized by them and have better interaction and collaboration, without the need for training. The system offers an ubiquitous recognition system, using smart devices like smart-phones or smart-wristbands. When a familiar person is detected in the house, then a sound is reproduced on smart speakers, in order to stimulate the sufferer's memory. The system identified all users and reproduced the appropriate sound at $100 \%$ of the cases.

The main challenge of the proposed solution was the inclusion of the system in a typical household without affecting the day-to-day living of the sufferer. This was achieved exploiting commonly used technology in smart devices. The developed system is not visible to the sufferer, disguised as a typical 


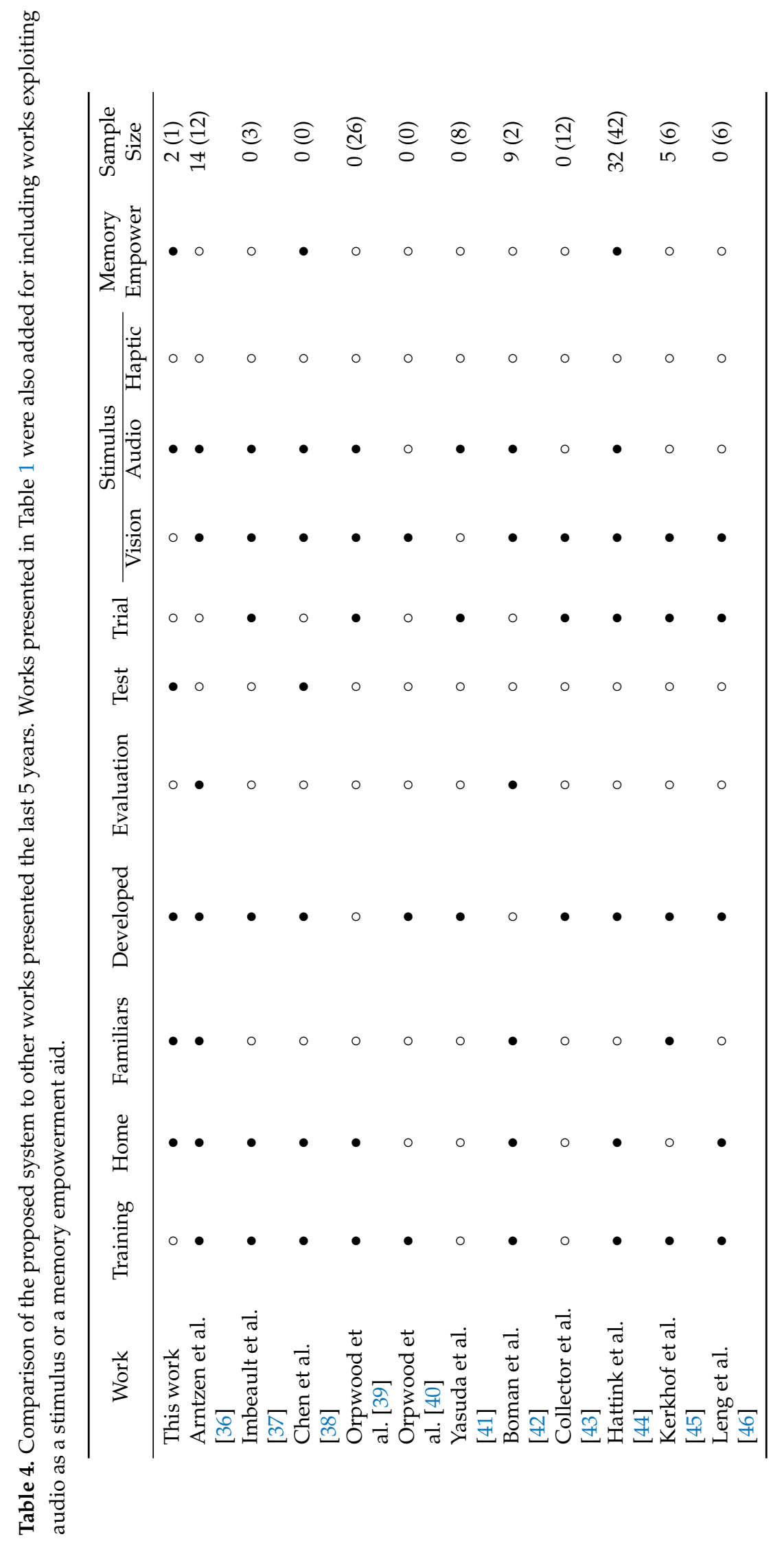


speaker. The tests that were conducted, prove the expected functionality. Exploring the recently reported research works, it was observed that only few of them consider sound as a memory stimulus. To the best of the authors' knowledge, this is the first acoustic-based system of its kind for assisting person recognition for people suffering from dementia.

Acknowledgments: The IEEE EPICS program funded the equipment for training purposes. The research was supported by the prize received on 2017 from IEEE Region 8 Mind the Gap student contest.

Conflicts of Interest: The funding sponsors had no role in the design of the study; in the collection, analyses, or interpretation of data; in the writing of the manuscript, and in the decision to publish the results.

\section{Abbreviations}

The following abbreviations are used in this manuscript:

AES: Advanced Encryption Standard

API: Application Program Interface

DB: Database

DDNS: Dynamic Domain Name System

ID: Identification

IEEE: Institute of Electrical and Electronics Engineers

ISP: Internet Service Provider

JSON: JavaScript Object Notation

MAC: Media Access Control

OS: Operating System

PHP: Hypertext Preprocessor

REST: Representational State Transfer

RSSI: Received Signal Strength Indicator

SaaS: Software as a Service

SHA: Secure Hash Algorithm

URL: Uniform Resource Locator

VM: Virtual Machine

Wi-Fi: Wireless Fidelity

\section{References}

1. Organization, W.H.; others. Meeting on the Implementation of the global action plan of the public health response on dementia 2017-2025: meeting report: 11-12 December 2017, World Health Organization, Geneva, Switzerland. Technical report, World Health Organization, 2018.

2. Sixsmith, A.; Gibson, G. Music and the wellbeing of people with dementia. Ageing $\mathcal{E}$ Society 2007, 27, 127-145.

3. McDermott, O.; Orrell, M.; Ridder, H.M. The importance of music for people with dementia: the perspectives of people with dementia, family carers, staff and music therapists. Aging $\mathcal{E}$ Mental Health 2014, 18, 706-716.

4. Holmes, C.; Knights, A.; Dean, C.; Hodkinson, S.; Hopkins, V. Keep music live: music and the alleviation of apathy in dementia subjects. International Psychogeriatrics 2006, 18, 623-630.

5. Vanstone, A.D.; Cuddy, L.L. Musical memory in Alzheimer disease. Aging, Neuropsychology, and Cognition 2009, 17, 108-128.

6. Boger, J.; Hoey, J.; Poupart, P.; Boutilier, C.; Fernie, G.; Mihailidis, A. A planning system based on Markov decision processes to guide people with dementia through activities of daily living. IEEE Transactions on Information Technology in Biomedicine 2006, 10, 323-333.

7. Jean-Baptiste, E.M.; Mihailidis, A. Benefits of automatic human action recognition in an assistive system for people with dementia. Humanitarian Technology Conference (IHTC), 2017 IEEE Canada International. IEEE, 2017, pp. 61-65.

8. Zhang, S.; McClean, S.; Scotney, B.; Hong, X.; Nugent, C.; Mulvenna, M. Decision support for alzheimer's patients in smart homes. Computer-Based Medical Systems, 2008. CBMS'08. 21st IEEE International Symposium on. IEEE, 2008, pp. 236-241. 
9. Osamu, T.; Ryu, T.; Hayashida, A.; Moshnyaga, V.; Sakamoto, D.; Imai, Y.; Shibata, T. A smart system for home monitoring of people with cognitive impairment. Humanitarian Technology Conference-(IHTC), 2014 IEEE Canada International. IEEE, 2014, pp. 1-4.

10. Richter, J.; Findeisen, M.; Hirtz, G. Assessment and care system based on people detection for elderly suffering from dementia. Consumer Electronics-Berlin (ICCE-Berlin), 2015 IEEE 5th International Conference on. IEEE, 2015, pp. 59-63.

11. Amiribesheli, M.; Bouchachia, A. Towards dementia-friendly smart homes. 2016 IEEE 40th annual computer software and applications conference (COMPSAC). IEEE, 2016, pp. 638-647.

12. Khan, S.S.; Zhu, T.; Ye, B.; Mihailidis, A.; Iaboni, A.; Newman, K.; Wang, A.H.; Martin, L.S. DAAD: A Framework for Detecting Agitation and Aggression in People Living with Dementia Using a Novel Multi-modal Sensor Network. Data Mining Workshops (ICDMW), 2017 IEEE International Conference on. IEEE, 2017, pp. 703-710.

13. Mulvenna, M.; Zheng, H.; Bond, R.; McAllister, P.; Wang, H.; Riestra, R. Participatory design-based requirements elicitation involving people living with dementia towards a home-based platform to monitor emotional wellbeing. 2017 IEEE International Conference on Bioinformatics and Biomedicine (BIBM). IEEE, 2017, pp. 2026-2030.

14. Elakkiya, J.; Gayathri, K. Progressive assessment system for dementia care through smart home. Algorithms, Methodology, Models and Applications in Emerging Technologies (ICAMMAET), 2017 International Conference on. IEEE, 2017, pp. 1-5.

15. Kimino, K.; Ishii, H.; Aljehani, M.; Inoue, M. Early detection system of dementia based on home behaviors and lifestyle backgrounds. Consumer Electronics (ICCE), 2018 IEEE International Conference on. IEEE, 2018, pp. 1-2.

16. Schinle, M.; Papantonis, I.; Stork, W. Personalization of monitoring system parameters to support ambulatory care for dementia patients. Sensors Applications Symposium (SAS), 2018 IEEE. IEEE, 2018, pp. 1-6.

17. Ceccacci, S.; Generosi, A.; Giraldi, L.; Mengoni, M. An user-centered approach to design smart systems for people with dementia. Consumer Electronics-Berlin (ICCE-Berlin), 2017 IEEE 7th International Conference on. IEEE, 2017, pp. 273-278.

18. Luckner, N.; Kayali, F.; Purgathofer, P.; Werner, K.; Victoria, M.C. Technological interventions to increase mobility of older adults with dementia. 2018 IEEE 6th International Conference on Serious Games and Applications for Health (SeGAH). IEEE, 2018.

19. Naranjo-Hernández, D.; Roa, L.M.; Reina-Tosina, J.; Estudillo-Valderrama, M.A. SoM: a smart sensor for human activity monitoring and assisted healthy ageing. IEEE transactions on biomedical engineering 2012, 59, 3177-3184.

20. Kasliwal, M.H.; Patil, H.Y. Smart location tracking system for dementia patients. Advances in Computing, Communication and Control (ICAC3), 2017 International Conference on. IEEE, 2017, pp. 1-6.

21. Wu, H.K.; Hung, T.W.; Wang, S.H.; Wang, J.W. Development of a shoe-based dementia patient tracking and rescue system. 2018 IEEE International Conference on Applied System Invention (ICASI). IEEE, 2018, pp. 885-887.

22. Alam, R.; Anderson, M.; Bankole, A.; Lach, J. Inferring physical agitation in dementia using smartwatch and sequential behavior models. Biomedical \& Health Informatics (BHI), 2018 IEEE EMBS International Conference on. IEEE, 2018, pp. 170-173.

23. Hanna, D.; Ferworn, A.; Lukaczyn, M.; Abhari, A.; Lum, J. Using Unmanned Aerial Vehicles (UAVs) in locating wandering patients with dementia. Position, Location and Navigation Symposium (PLANS), 2018 IEEE/ION. IEEE, 2018, pp. 809-815.

24. Tung, J.; Snyder, H.; Hoey, J.; Mihailidis, A.; Carrillo, M.; Favela, J. Everyday patient-care technologies for Alzheimer's disease. IEEE Pervasive Computing 2013, 12, 80-83.

25. Ferreira, L.D.A.; Cameirão, M.S.; i Badia, S.B. Music-based assistive feedback system for the exploration of virtual environments in individuals with dementia. Virtual Rehabilitation (ICVR), 2017 International Conference on. IEEE, 2017, pp. 1-7.

26. Nishimura, R.; Uchiya, T.; Hirano, T.; Sakurai, M. Proposal of reminiscence therapy system using spoken dialog to suppress dementia. Consumer Electronics (GCCE), 2017 IEEE 6th Global Conference on. IEEE, 2017, pp. 1-2. 
27. Siriaraya, P.; Ang, C.S. Developing virtual environments for older users: Case studies of virtual environments iteratively developed for older users and people with dementia. Information Technology (INCIT), 2017 2nd International Conference on. IEEE, 2017, pp. 1-6.

28. Hu, P.; Dhelim, S.; Ning, H.; Qiu, T. Survey on fog computing: architecture, key technologies, applications and open issues. Journal of Network and Computer Applications 2017, 98, 27-42.

29. Yi, S.; Hao, Z.; Qin, Z.; Li, Q. Fog computing: Platform and applications. 2015 Third IEEE Workshop on Hot Topics in Web Systems and Technologies (HotWeb). IEEE, 2015, pp. 73-78.

30. Mazuelas, S.; Bahillo, A.; Lorenzo, R.M.; Fernandez, P.; Lago, F.A.; Garcia, E.; Blas, J.; Abril, E.J. Robust indoor positioning provided by real-time RSSI values in unmodified WLAN networks. IEEE Journal of selected topics in signal processing 2009, 3, 821-831.

31. Wang, Y.; Yang, X.; Zhao, Y.; Liu, Y.; Cuthbert, L. Bluetooth positioning using RSSI and triangulation methods. Consumer Communications and Networking Conference (CCNC), 2013 IEEE. IEEE, 2013, pp. 837-842.

32. Giovanelli, D.; Farella, E. Rssi or time-of-flight for bluetooth low energy based localization? an experimental evaluation. 2018 11th IFIP Wireless and Mobile Networking Conference (WMNC). IEEE, 2018, pp. 1-8.

33. Ghose, A.; Bhaumik, C.; Chakravarty, T. Blueeye: A system for proximity detection using bluetooth on mobile phones. Proceedings of the 2013 ACM conference on Pervasive and ubiquitous computing adjunct publication. ACM, 2013, pp. 1135-1142.

34. Kaczmarek, M.; Ruminski, J.; Bujnowski, A. Accuracy analysis of the RSSI BLE SensorTag signal for indoor localization purposes. Computer Science and Information Systems (FedCSIS), 2016 Federated Conference on. IEEE, 2016, pp. 1413-1416.

35. King, A.C.; Dwan, C. Electronic memory aids for people with dementia experiencing prospective memory loss: A review of empirical studies. Dementia 2017, p. 1471301217735180.

36. Arntzen, C.; Holthe, T.; Jentoft, R. Tracing the successful incorporation of assistive technology into everyday life for younger people with dementia and family carers. Dementia 2016, 15, 646-662.

37. Imbeault, H.; Gagnon, L.; Pigot, H.; Giroux, S.; Marcotte, N.; Cribier-Delande, P.; Duval, J.; Bocti, C.; Lacombe, G.; Fülöp, T.; others. Impact of AP@ LZ in the daily life of three persons with Alzheimer's disease: long-term use and further exploration of its effectiveness. Neuropsychological rehabilitation 2018, 28, 755-778.

38. Chen, J.P.; Desai, J.; Patel, V. MemAid-A Therapeutic Application for Dementia Patients and Caregivers, 2015.

39. Orpwood, R.; Sixsmith, A.; Torrington, J.; Chadd, J.; Gibson, G.; Chalfont, G. Designing technology to support quality of life of people with dementia. Technology and Disability 2007, 19, 103-112.

40. Orpwood, R.; Bjørneby, S.; Hagen, I.; Mäki, O.; Faulkner, R.; Topo, P. User involvement in dementia product development. Dementia 2004, 3, 263-279.

41. Yasuda, K.; Misu, T.; Beckman, B.; Watanabe, O.; Ozawa, Y.; Nakamura, T. Use of an IC recorder as a voice output memory aid for patients with prospective memory impairment. Neuropsychological Rehabilitation 2002, 12, 155-166.

42. Boman, I.L.; Persson, A.C.; Bartfai, A. First steps in designing an all-in-one ICT-based device for persons with cognitive impairment: evaluation of the first mock-up. BMC geriatrics 2016, 16, 61.

43. Collerton, D.; Forster, E.; Packham, D. An exploratory study of the effectiveness of memory aids for older people living in supported accommodation. Journal of Applied Gerontology 2014, 33, 963-981.

44. Hattink, B.; Meiland, F.; Overmars-Marx, T.; de Boer, M.; Ebben, P.; van Blanken, M.; Verhaeghe, S.; Stalpers-Croeze, I.; Jedlitschka, A.; Flick, S.; others. The electronic, personalizable Rosetta system for dementia care: exploring the user-friendliness, usefulness and impact. Disability and Rehabilitation: Assistive Technology 2016, 11, 61-71.

45. Kerkhof, Y.J.; Rabiee, F.; Willems, C.G. Experiences of using a memory aid to structure and support daily activities in a small-scale group accommodation for people with dementia. Dementia 2015, 14, 633-649.

46. Leng, F.Y.; Yeo, D.; George, S.; Barr, C. Comparison of iPad applications with traditional activities using person-centred care approach: impact on well-being for persons with dementia. Dementia 2014, 13, $265-273$. 